https://doi.org/10.29296/25877305-2018-06-13

КОГНИТИВНЫЕ РАССТРОЙСТВА

В ПЕРИОД ГОРМОНАЛЬНОЙ ПЕРЕСТРОЙКИ У МУЖЧИН

\title{
И ЖЕНЩИН
}

Э. Сатардинова, кандидат медицинских наук Иркутская государственная медицинская академия последипломного образования E-mail: irkmapo@irk.ru

В статье рассмотрены нарушения когнитивного статуса у пациентов С гормональными нарушениями и негативным вариантом биологического возраста, а также пути коррекции указанных нарушений с помощью физической активности, когнитивной гимнастики, дополнительного применения ноотропных препаратов.

Ключевые слова: неврология, эндокринология, когнитивные расстройства, гормональная перестройка, климактерический период, преждевременное старение, возрастной андрогенный десицит, биологический возраст.

Для цитирования: Сатардинова Э. Когнитивные расстройства в период гормональной перестройки у мужчин и женщин // Врач. - 2018; 29 (6): 59-62. https://doi.org/10.29296/25877305-2018-06-13

Гормональная перестройка организма у мужчин и женщин начинается уже в среднем возрасте и может сопровождаться развитием признаков преждевременного старения. Основными гериатрическими синдромами, ассоциированными с синдромом преждевременного старения, являются: саркопения (возрастное снижение мышечной массы и силы), мальнутриция (дефицит питания и потеря массы тела), когнитивные расстройства (КР), синдром гипомобильности (ограничения передвижения), синдром нарушений сна и др. Под гормональной перестройкой понимается развитие климактерического периода - у женщин и возрастного андрогенного дефицита - у мужчин [1-3].

Одной из важных проблем урбанистического современного общества являются ранние проявления КР и гиподиагностика таких состояний. В частности, все большую популярность приобретает поиск причин развития ранних когнитивных нарушений (КН). Изучаются взаимосвязь нарушений гормонального фона и развития когнитивного дефицита, а также пути их коррекции [2, 3].

Так, в 2015 г. в США предпринята попытка изучить ассоциации между гормонами половой системы и когнитивной функцией (КФ) [4]. Высокое содержание в 
сыворотке крови эстрадиола коррелировало с лучшей КФ у пациентов пожилого возраста. Значительного влияния других гормонов не обнаружено. Однако авторы данного исследования также акцентируют внимание на том, что в ходе эксперимента с пожилыми людьми проводили когнитивные тренинги, что может быть основной причиной таких результатов.

В 2015 г. группа ученых из Австралии [5] также пыталась определить взаимосвязь когнитивного дефицита с уровнем тестостерона, дигидротестостерона и эстрадиола в рамках проекта Concord Health and Aging in Men (СНАМР). Однако ни один из базовых репродуктивных гормонов не предсказывал когнитивного спада у мужчин пожилого возраста без деменции в течение 5 лет.

В направленном воздействии на компенсирование КР и предотвращение преждевременного старения важны немедикаментозные методы профилактики, к которым относятся физические тренировки и дополнительный прием ноотропов. К сожалению, исследований в области разработки и реализации программ профилактики в гериатрической практике недостаточно $[3,6,7]$.

Актуальность нашей работы определили дефицит доказательных исследований в области разработки программ для профилактики развития основных гериатрических синдромов, имеющих важное превентивное значение.

В исследовании участвовали 1080 пациентов (по 540 женщин и мужчин). У всех определяли биологический возраст (БВ) - его позитивный $(+)$ и негативный (-) варианты, причем последний свидетельствует о признаках преждевременного старения.

Биологический возраст мы устанавливали по формуле для определения биологического возраста по методике В.П. Войтенко:

$$
\begin{gathered}
\text { мужчины }=26,985+0,215 \cdot \text { САД- } 0,149 \cdot \\
\text { ЗДВ-0,151 • СБ }+0,723 \cdot \text { СО3; } \\
\text { женщины }=-1,463+0,415 \cdot \text { ПАД- } 0,141 \\
\text { СБ }+0,248 \cdot \text { МТ+0,694 } \bullet \text { СО3, }
\end{gathered}
$$

где САД - систолическое, ПАД - пульсовое АД, мм рт. ст.; ЗДВ - продолжительность задержки дыхания после глубокого вдоха; МТ - масса тела, кг; СБ - статическая балансировка; СО3 - субъективная оценка здоровья.

Результаты сравнивали с хронологическим (паспортным) возрастом. Если показатели превышали его, пациентов относили к группе с (-)-вариантом БВ; если результаты были ниже хронологического возраста, пациентов включали в группу с (+)-вариантом БВ. Пациентов с нормальным вариантом БВ в исследование не включали. Для объективизации данных исследования подбирали однородные в течение 5 лет группы.

Из 540 женщин с нарушениями гормонального фона в виде пред- или климактерического синдро- ма 270 были в возрасте 44-54 лет (средний возраст $49,1 \pm 2,2$ года), из них 150 человек с (-)-вариантом и $120-$ с (+)-вариантом БВ и 270 женщин - в возрасте 55-64 лет (средний возраст 57,2 2 ,4 года), из них 150 - с (-)-вариантом и $120-$ с (+)-вариантом БВ.

Из 540 мужчин с нарушениями гормонального фона в виде возрастного андрогенного дефицита 270 пациентов были в возрасте 44-54 лет (средний возраст $51,1 \pm 2,3$ года), в том числе $150-$ с $(-)$-вариантом и 120 - с (+)-вариантом БВ; из еще 270 обследованных в возрасте 55-64 лет (средний возраст 59,2 2 ,4 года) у 150 был (-)-вариант, у $120-(+)$-вариант БВ.

В зависимости от проводимых терапевтических манипуляций все пациенты были разделены на 3 группы:

- в 1-й (контрольной) группе пациенты $(\mathrm{n}=90)$ получали стандартные рекомендации врача без дополнительного режима физической активности и дополнительного приема ноотропов, включавшие необходимую стандартную терапию по клиническим рекомендациям по поводу пред- или климактерического синдрома и возрастного андрогенного дефицита в виде гормональных лекарственных препаратов;

- во 2-й группе - пациенты $(\mathrm{n}=90)$ дополнительно к стандартным рекомендациям занимались аэробными тренировками 2 раза в неделю; кроме того, ежедневно у них были прогулки продолжительностью не менее 30 мин;

- в 3-й группе пациенты (n=90) дополнительно к стандартным рекомендациям и специальным тренировкам (как во 2-й группе), ежедневно занимались когнитивной гимнастикой в течение 30 мин; кроме того, им были назначены ноотропные препараты (гинкго билоба - по 40 мг 3 раза в день по инструкции).

Исследование проводили на протяжении 6 мес. Для оценки КФ использовалась русскоязычная версия шкалы опросника MMSE (Mini Mental State Examenation).

В основе статистических методов обработки данных лежал метод статистических регистров с динамической рандомизацией по исследуемым признакам. При обработке данных исследования рассчитывали средние абсолютные и относительные показатели + ошибку среднего; выполнена оценка значимости различий 2 совокупностей с применением t-критерия Стьюдента (различия считали достоверными при $\mathrm{t}>2$; $\mathrm{p}<0,05)$. Установлена корреляционная связь.

Одной из задач исследования была оценка эффективности физических тренировок, когнитивной гимнастики и дополнительного назначения ноотропов путем определения КФ у пациентов с нарушениями гормонального фона и признаками преждевременного старения с применением опросника MMSE (табл. 1).

Так, у женщин в возрасте от 45 до 54 лет при $(+)$-варианте БВ в 1-й группе среднее значение до начала исследования составило $24,5 \pm 0,6$ балла, спустя 
6 мес $-25,5 \pm 0,6$ балла, во 2-й группе - соответственно $24,0 \pm 0,6$ и $27,0 \pm 1,1$ балла; такие изменения относятся к преддементным КН ( $<<0,05$; различия достоверны по сравнению с контролем). В 3-й группе этот показатель до начала исследования составил $24,0 \pm 0,6$

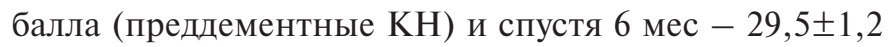
балла (вариант нормы; $\mathbf{p}<0,05$ ). Полученные данные позволяют сделать вывод, что у женщин в возрасте 45-54 года в пред- и климактерическом периоде без преждевременного старения изначально имеются преддементные КН, которые удается достоверно нормализовать с помощью физической активности, когнитивной гимнастики и дополнительного применения ноотропов.

У женщин рассматриваемой возрастной группы при (-)-варианте БВ через 6 мес изучаемый показатель в 1-й терапевтической группе составил $23,5 \pm 0,8$ балла, во 2-й $-25,5 \pm 1,2$ балла, в $3-и ̆ ~-27,0 \pm 1,2$ балла $(\mathrm{p}<0,05$ между группами и по сравнению с контролем). Такие изменения относятся к преддементным KH.

У женщин в возрасте от 55 до 64 лет показатели КФ были ниже, чем в предыдущей группе. Так, при (+)-варианте БВ в 1-й группе среднее значение до начала исследования составило $23,5 \pm 0,6$ балла, через 6 мес - 24,5 $\pm 0,8$ балла (преддементные КН), во 2-й соответственно $24,0 \pm 0,6$ и $26,0 \pm 1,2$ балла (также преддементные КН), $<<0,05$ по сравнению с контролем; в 3 -й группе $-23,5 \pm 0,6$ балла до начала исследования и $28,5 \pm 1,2$ балла через 6 мес (вариант нормы; $<<0,05$ по сравнению с показателем в 1-й группе, а также в кон- троле). Эти данные позволяют сделать вывод, что у женщин возрасте 55-64 лет в пред- и климактерическом периоде без преждевременного старения изначально имеются преддементные КН, которые удается достоверно нормализовать с помощью физической активности, когнитивной гимнастики и дополнительного применения ноотропов, однако отмечаемые у них показатели ниже, чем у женщин в возрасте 45-54 года.

У женщин в возрастной группе от 55 до 64 лет при (-)-варианте БА через 6 мес в 1-й терапевтической группе изучаемый показатель составил $23,5 \pm 0,8$ балла, во 2 -й - 24,5 $\pm 1,2$ ( $<<0,05$ между группами), в 3-й $27,0 \pm 1,2$ балла ( $\mathrm{p}<0,05$ по сравнению с показателями в 2 других группах и с контролем). Эти показатели, как и в предыдущей возрастной группе, относятся к преддементным КН.

Полученные результаты показывают, что у женщин с гормональными перестройками и преждевременным старением имеются преддементные нарушения КФ, которые не удается ликвидировать с помощью физической активности, когнитивной гимнастики и дополнительного приема ноотропов как в возрасте 45-54 лет, так и в более старшей возрастной группе.

У мужчин нами обнаружены схожие с выявленными у женщин закономерности (табл. 2).

Отметим, что у мужчин с возрастным андрогенным дефицитом в возрасте 55-64 лет при (-)-варианте БВ показатели КФ ниже, чем у женщин: через 6 мес исследования в 1 -й группе $-23,5 \pm 0,8$ балла, во 2 -й $23,5 \pm 1,2$ балла (различия недостоверны; $p>0,05$ ), в 3-й группе $-26,0 \pm 1,2$ балла ( $<00,05$ по сравнению с 1 -й,

\begin{tabular}{|c|c|c|c|c|c|c|}
\hline Группа терапии & до начала исследования & (+)-вариант БВ & (-)-вариант БВ & до начала исследования & (+)-вариант БВ & (-)-вариант БВ \\
\hline 1-я & $24,5 \pm 0,6$ & $25,5 \pm 0,6$ & $23,5 \pm 0,8^{2}$ & $23,5 \pm 0,6$ & $24,5 \pm 0,8$ & $23,5 \pm 0,8$ \\
\hline 3-я & $24,0 \pm 0,6$ & $29,5 \pm 1,2^{1,6,7}$ & $27,0 \pm 1,2^{1,2,6,7}$ & $23,5 \pm 0,6$ & $28,5 \pm 1,2^{1,3,6,7}$ & $27,0 \pm 1,2^{1,6,7}$ \\
\hline \multicolumn{7}{|c|}{ 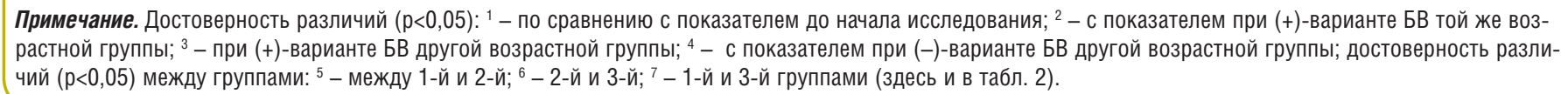 } \\
\hline
\end{tabular}

\begin{tabular}{|c|c|c|c|c|c|c|}
\hline \multicolumn{7}{|c|}{ 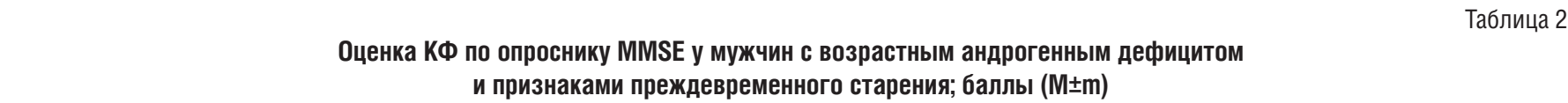 } \\
\hline \multirow{2}{*}{ Группа терапии } & \multicolumn{3}{|c|}{ Возрастная группа от 45 до 54 лет } & \multicolumn{3}{|c|}{ Возрастная группа от 55 до 64 лет } \\
\hline & до начала исследования & (+)-вариант БВ & (-)-вариант БВ & до начала исследования & (+)-вариант БВ & (-)-вариант БВ \\
\hline 1-я & $24,5 \pm 0,6$ & $24,5 \pm 0,6$ & $22,0 \pm 0,8^{2}$ & $22,5 \pm 0,4$ & $23,5 \pm 0,8$ & $23,5 \pm 0,8^{2}$ \\
\hline 2-я & $24,0 \pm 0,6$ & $26,0 \pm 1,1^{1,5}$ & $24,5 \pm 1,2^{2}$ & $23,0 \pm 0,4$ & $26,0 \pm 1,2^{1,5}$ & $23,5 \pm 1,2^{2}$ \\
\hline 3-я & $24,5 \pm 0,6$ & $29,5 \pm 1,2^{1,6,7}$ & $26,0 \pm 1,2^{1,2,6,7}$ & $22,5 \pm 0,4$ & $28,5 \pm 1,2^{1,3,7}$ & $26,0 \pm 1,2^{1,2,4,6,7}$ \\
\hline
\end{tabular}


Таблица 3

Корреляционная связь КН во всех случаях $(p<0,05)$

\begin{tabular}{|lcc|}
\hline \multirow{2}{*}{ Причины обращения } & Женщины & Мужчины \\
\cline { 2 - 3 } & $\begin{array}{c}\text { коэффициент } \\
\text { корреляции (r) }\end{array}$ \\
\hline Сухость кожи & $+0,7$ & $+0,6$ \\
\hline Отечность & $+0,9$ & $+0,8$ \\
\hline Ощущение жара & $+0,8$ & $+0,8$ \\
\hline Потливость & $+0,8$ & $+0,8$ \\
\hline Головная боль & $+0,8$ & $+0,9$ \\
\hline Колебания АД & $+0,9$ & $+0,9$ \\
\hline Вазомоторный ринит & $+0,6$ & $+0,6$ \\
\hline Сухость слизистых оболочек половых путей & $+0,9$ & $+0,9$ \\
\hline Тревожно-депрессивный синдром & $+0,9$ & $+0,8$ \\
\hline Субъективно пониженный фрон настроения & $+0,8$ & $+0,8$ \\
\hline Синдром хронической усталости & $+0,9$ & $+0,9$ \\
\hline
\end{tabular}

2-й и контрольной группами). Однако эти показатели, как и у мужчин в возрасте 45-54 лет и женщин, относятся к преддементным КН.

Представленные в табл. 2 данные доказывают, что у мужчин с возрастным андрогенным дефицитом и преждевременным старением имеются преддементные нарушения КФ: ликвидировать их с помощью физической активности, когнитивной гимнастики и дополнительного приема ноотропов не удается как в возрасте 45-54 лет, так и в более старшей возрастной группе.

Отмечалась достоверная сильная положительная корреляция КН с ощущениями опрошенных пациентов (табл. 3).

Так, у женщин КН имеют сильную положительную корреляционную связь с отечностью, колебаниями АД, сухостью слизистых оболочек половых путей, тревожно-депрессивным синдромом, синдромом хронической усталости $(\mathrm{r}=+0,9 ; \mathrm{p}<0,05)$.

У мужчин КН имеют сильную положительную корреляционную связь с головной болью, колебаниями АД, сухостью слизистых оболочек половых путей и синдромом хронической усталости $(\mathrm{r}=+0,9 ; \mathrm{p}<0,05)$.

$$
* * *
$$

Автор заявляет об отсутствии конфликта интересов.

\section{Литература}

1. Захаров В.В. Ведение пациентов с когнитивными нарушениями // РМЖ. - 2007; 6: 510-6.

2. Слободин Т.А., Горева А.В. Когнитивный резерв: причины снижения и защитные механизмы // Междунар. неврол. журн. - 2012; 3 (49): 161-5.

3. Ильницкий А.Н., Прощаев К.И., Варавина Л.Е. и др. Синдром старческой астении (frailty): клиника, диагностика, лечение, профилактика // Врач. - 2014; 6: 13-6.

4. Hsu B., Cumming R., Waite L. et al. Longitudinal Relationships between Reproductive Hormones and Cognitive Decline in Older Men: The Concord Health and Ageing in Men Project // J. Clin. Endocrinol. Metab. - 2015; 100 (6): 2223-30.

5. Boss L., Kang D., Bergstrom N. et al. Endogenous sex hormones and cognitive function in the elderly // Aging Clin. Exp. Res. - 2015; 27 (4): 515-21.

6. Nyberg F., Hallberg M. Growth hormone and cognitive function // Nat. Rev. Endocrinol. - 2013; 9 (6): 357-65.

7. Ferreira Santana R., Batista Rosa T., Gonçalves Aquino R. et al. Maintenance of functional capacity in cognitive stimulation subgroups // Invest. Educ. Enferm. - 2016; 34 (3): 493-501.

\section{COGNITIVE IMPAIRMENT IN THE MALE AND FEMALE HORMONAL RESTRUCTURING PERIOD \\ E. Satardinova, Candidate of Medical Sciences \\ Irkutsk State Medical Academy of Postgraduate Education}

The paper considers the impaired cognitive status of patients with hormonal disorders and a negative variant of biological age, as well as ways to correct the above disorders through physical activity, cognitive gymnastics, and additional use of nootropics.

Key words: neurology, endocrinology, cognitive impairment, hormonal restructuring, menopause, premature aging, age-related androgen deficiency, biological age. For citation: Satardinova E. Cognitive impairment in the male and female hormonal restructuring period // Vrach. - 2018; 29 (6): 59-62. https://doi. org/10.29296/25877305-2018-06-13 